
PPeriodica Polytechnica
Architecture

48(2), pp. 113-121, 2017

https://doi.org/10.3311/PPar.11829

Creative Commons Attribution (i)

RESEARCH ARTICLE

\section{Experimental Space and Form Creation on the Borderline in Art and Architecture}

\author{
Gábor Üveges $^{1 *}$
}

Received 14 December 2017; accepted 14 February 2018

\begin{abstract}
In the process of the specialisation of arts and sciences and the fragmentation of knowledge, architecture - in certain aspects has isolated itself from the other disciplines of fine arts. Yet, distinctive points of connection have continuously persisted between them. The ability to understand, oversee and associate the knowledge accumulated in the different disciplines also has the potential to facilitate progress and inspiration, both in intellectuality as well as in the creation of forms and spaces. This paper demonstrates four distinct directions of the creative work at the Budapest University of Technology and Economics Department of Graphics, Form and Design, each of which aims to explore new territories in this unique borderline between arts and architecture through interdisciplinary approaches and interoperability. The first direction, titled "The architecture of the picture and the picture of architecture" was the earliest research project, best described as an architectonic planar and spatial thinking exercise. Another, still ongoing project series has been titled "Folding - creating forms and spaces in light of a philosophical concept". The third group of research projects could be best summarized under the title "Ideas and Forms-from conceptual thinking to visualisation". And the final direction "Research Team-experimental architectonic form creation in the virtual space" includes the most recent research projects conducted at the department. These four directions of research projects spanning over a 15-year period have confirmed that the border area between architecture and fine arts carries an exceptional potential in the development of visual thinking, spatial and formal sensitivity and creativity of architecture students.
\end{abstract}

\section{Keywords}

borderline in art and architecture, experimental space and form creation, folding, visualisation, virtual space, art programs for architecture students

\footnotetext{
${ }^{1}$ Department of Graphics, Form and Design, Faculty of Architecture, Budapest University of Technology and Economics, H-1521 Budapest, P.O.B. 91, Hungary

*Corresponding author, e-mail: uveges.g5@gmail.com
}

\section{Introduction}

Experimental form and space creation - primarily on the border between architecture and other disciplines of fine arts - has been a source of inspiration for both the creative and research work of the BME Department of Graphics, Form and Design for decades. Earlier efforts have been summarised in two large-scale and successful publications (Balogh, 1983; Dobó et al., 2004). In recent years, along similar aspirations but with fresh concepts and renewed inspirations, teams composed of teachers and students have conducted research programmes in four main directions. While the first research programme of the new stage has been ongoing for more than ten years, the most recent chapter of the creative and scientific exploration started less than a year ago.

\section{The architecture of the picture and the picture of architecture}

It began with an inspiring discovery that despite the specialisation and the apparent estrangement of architecture from other forms of fine arts, connecting fibres among them have not completely disappeared and that the paradigm shift of post-modernism brought new types of analogies not yet fully observed and researched. The recognition that in the second half of the $20^{\text {th }}$ century, similarities between architecture and fine art went far beyond merely superficial or coincidental resemblance, but can rather be regarded as deep correspondences. In the author's doctoral thesis, the analogies between works of outstanding fine artists and architects were analysed. Correspondence can be found between the works of the Hungarian painter Pál Deim and the American architect Richard Meier; the artist Richard Serra and the architect Frank O. Gehry; Minimal Art and Minimalist Architecture, or between László Moholy-Nagy and Peter Eisenman.

The challenge was how to transform the theoretical conclusion of the realisation into practical use, namely, how could we integrate the approaches of fine arts into architecture education. In particular, how can we achieve that not only outstanding practising architects would draw inspiration from art, but students of architecture too, right from the very beginning of their education. 

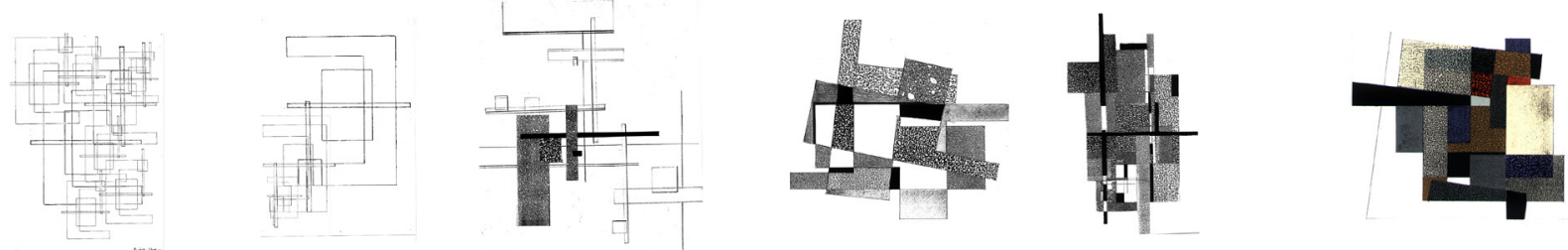

Fig. 1 Line drawings - Collages- Sketches, 2004

The proposal was that Geometrical Abstraction, as one of the most architectonic tendencies of fine arts, could serve as an excellent practising ground for students of architecture. Moreover, it can help develop students' visual thinking, visual language and grammar, architectonic space and form creation skills, as well as their creativity. It was due to its unprecedented ability to bridge the existing gap between architecture fine arts (arising from the differences between their form-language) in the early $20^{\text {th }}$ century that Geometrical Abstraction seemed more than suitable for this role. This rapprochement in formal language and partially in philosophy allowed for extraordinary structural similarities, like between the floor plan of Mies van der Rohe's 1923 brick country house project and Theo van Doesburg's 1918 Rhythm of a Russian Dance painting (Frampton, 1980:p.216). The distance between modernist architecture and abstract painting was reduced to the minimum by the commonality - not only in their mindset and artistic presuppositions but also in the shared formal toolset and space conception. Architecture and painting, probably for the first time in their course of history, became so close to each other that their analogies reached beyond the ultimate essential identity and manifested in direct and visible similarities between pictorial and architectural structures. Interactions between the disciplines at the time of the unfolding of modernist architecture, as well as in later periods of the $20^{\text {th }}$ century, was revealed

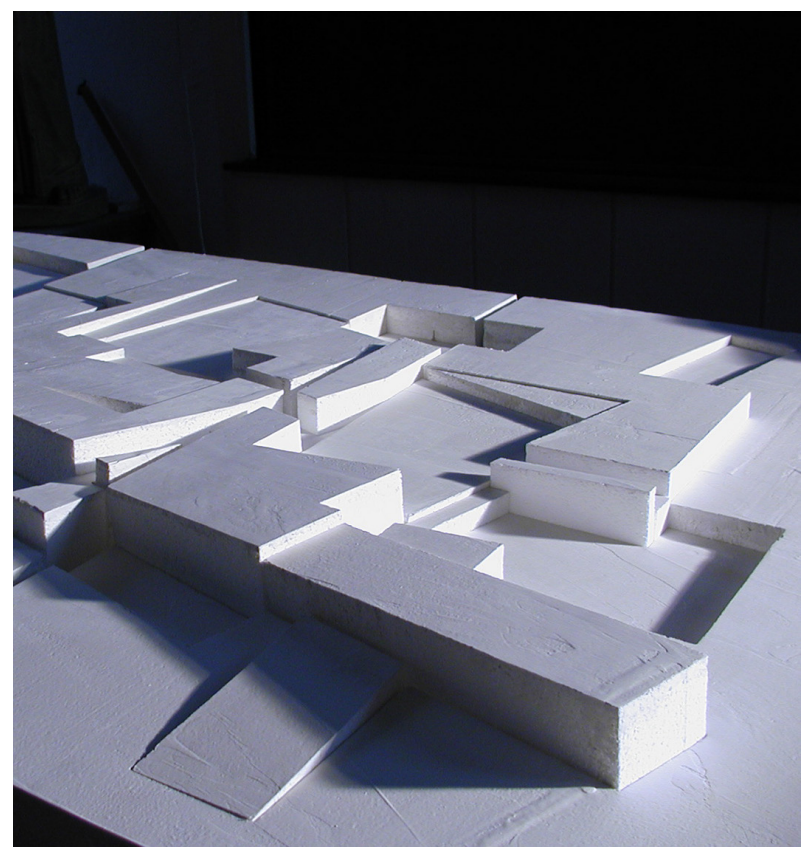

Fig. 2 Zsigmond Galló: Tectonic, OMDK. I. prize, 2005. far beyond indirect analogies, and more explicitly than ever before in both their attitude and formal creativity. Painting and architecture started to converge; painting turned architectonic, architecture employed the formal gestures - and partly the philosophy of the abstract and architectonic painting.

Structural principles of the picture meet those applied in architecture, and architectural theorems are reflected in the painting. Architecture and painting, functional and artistic thinking overlap each other. In the early $20^{\text {th }}$ century, the image of modern architecture emerges from the architecture of the abstract image. (Üveges, 2007:p.6)

The observation of the connecting role of Geometrical Abstraction between architecture and fine arts, as well as further additional considerations, initiated the idea of inviting and involving a prominent artist of geometrical abstraction in the education of architecture students and into our ongoing research projects - an instructor and source of inspiration to help introduce and accommodate geometrical abstraction to architecture education.

The first artist we worked with was Tamás Konok, the outstanding painter of abstract geometric compositions, and a competent theoretician, gifted with an extremely inspiring personality. Working with second-year students and inspired by Konok, we followed the logic of visual thinking and observed the evolution of this logic while transforming it from plane into

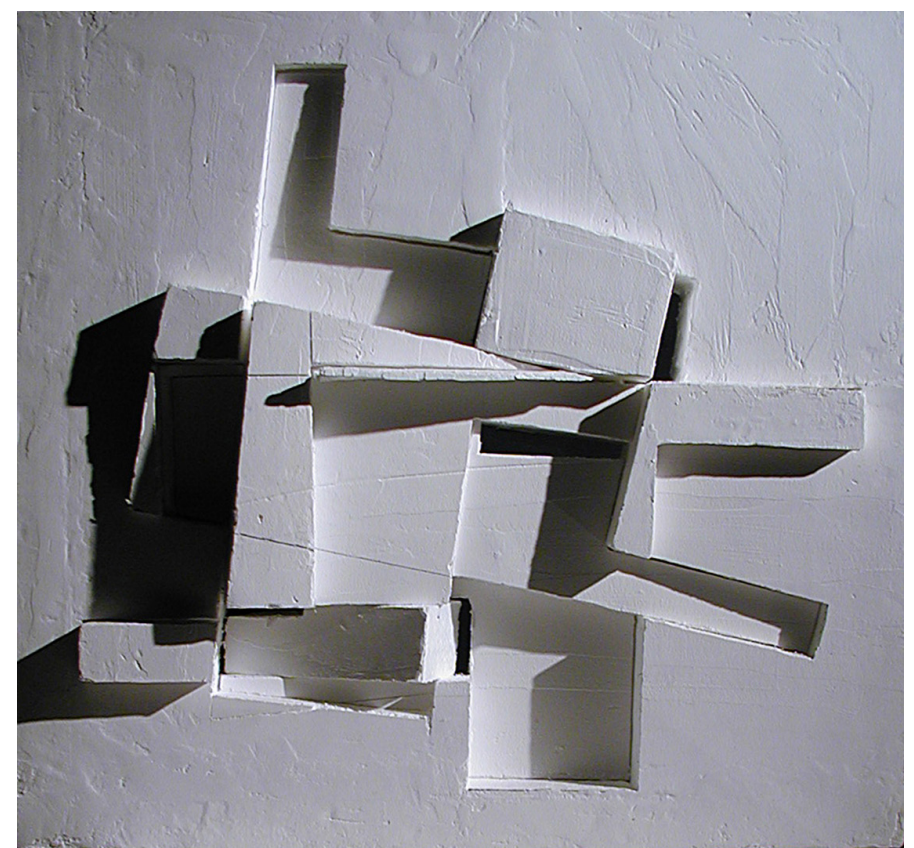

Fig. 3 Zsigmond Galló: Tectonic, sketch, TDK I. prize, 2004. 

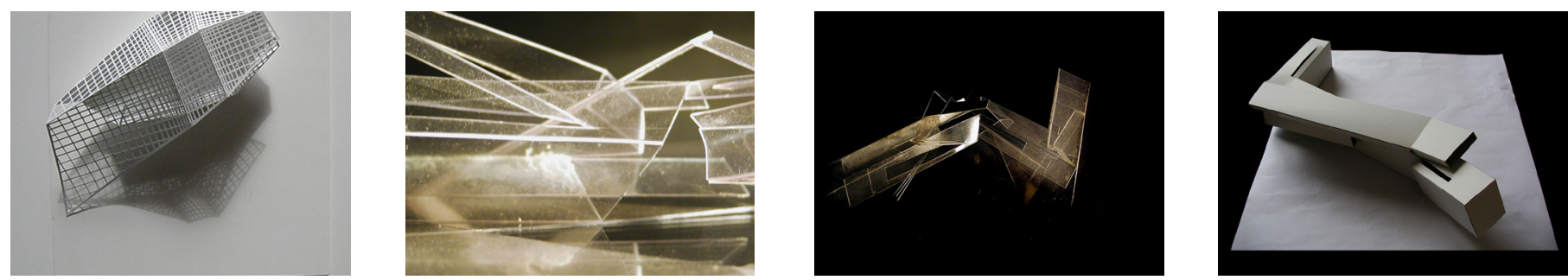

Fig. 4 Folding - Sketches, 2008 - 2014

space. Students started the thinking process in two dimensions, producing abstract compositions of architectonic linear drawings or - with Konok's words - the "thin-bodied architecture" (Beke, 2001:p.44). While converting the drawings into a collage, the students had the opportunity to learn about structure, rhythm and the tensioned balance of the composition.

In the next step, the two-dimensional composition was cut into a thick material. This step realised the transfiguration of the planar composition into a spatial structure, making it possible to follow and study the logic of visual thinking in three dimensions as well. The creative process resulted in a sort of embossment, which surprisingly gained different meanings depending on its positions. Holding the embossment in a vertical position, it reflected more the character of a sculpture, while lying the same artwork out horizontally gave the impression of an architectonic landscape.

The most successful work of the first phase - and the first tangible results of our long-term research in the field of experimental space and form creation - was the embossment titled "Tectonic" by Zsigmond Galló, winning first prize in sculpture category at the exhibition of the National Arts Students' Association in 2005 in Szeged.

\section{Folding}

Folding was the second direction of our creative research. It has been an ongoing project for about a decade. Folding is a late western descendant of the ancient traditional "origami" - "the art of folding paper" (Deleuze, 2006:p.7). Origami starts with a single square-shaped paper folded into an endless number of different sophisticated forms, through a variation and combination of halving and diagonal folds. It plays with symmetry in an ingenious and highly complex spatial and formal scheme. Whereas origami creates primarily symmetrical structures, folding employs an asymmetrical balance to create predominantly dynamic structures. Both techniques operate on the concept of folding, but while origami is often illustrative, folding creates abstract forms. Through the art of Folding, the simple act of folding paper becomes enriched with a unique new context, appearing also in late modern architecture and fine arts.

The concept of folding - at least in an artistic context, as in the interpretation of Gilles Deleuze - is a two-sided entity, similar in this regard to paper itself. From one side, folding bears a philosophical concept, while from the other, it reflects a spatial concept and a method of form creation. In the process of folding, the back and front of the paper switch places; inside turns outside and the outside becomes the inside. The alternation of folding and unfolding (Deleuze, 2006:p.9), or concealment and exposition (Heidegger, 1995:p.31) reveal what is behind the undulating surface.

From an architectural point-of-view, our creative and research work has gained inspiration from the folding period
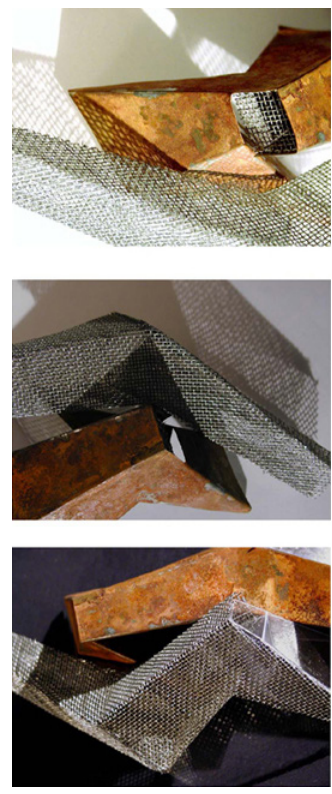

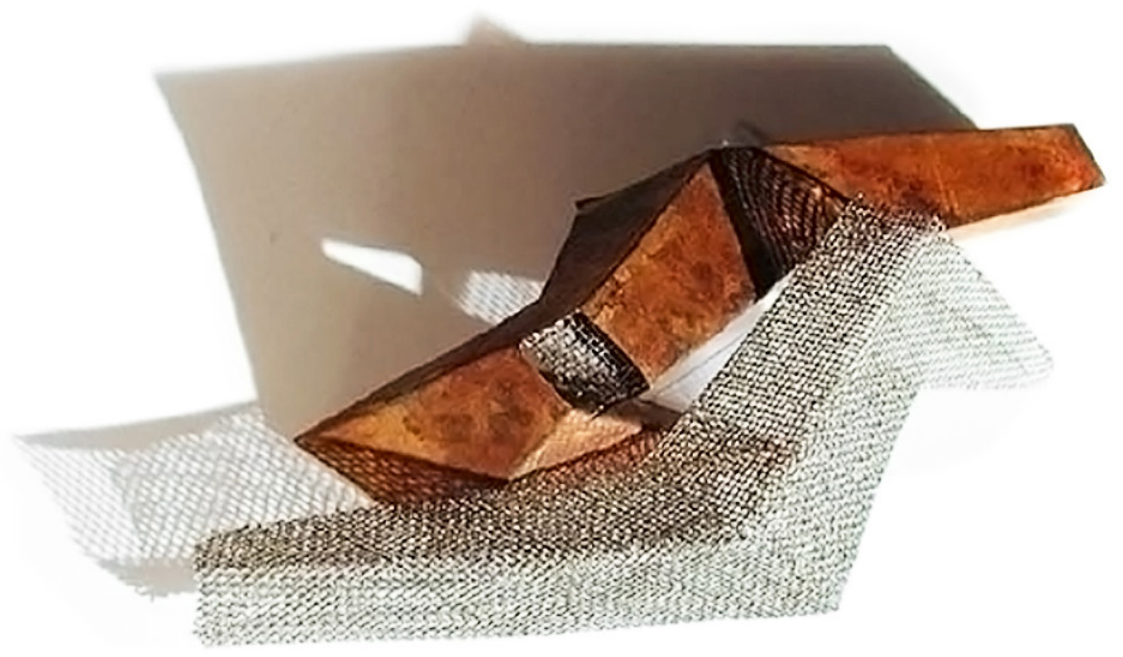

Fig. 5 Szabolcs Király: Folding, 2007 


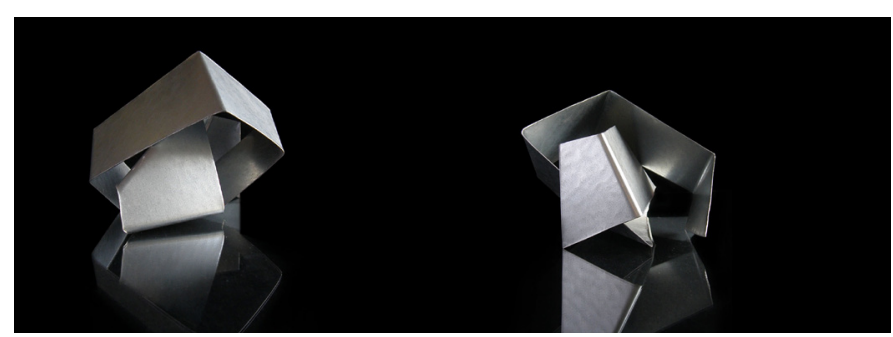

Fig. 6 Árpád Nagy: Aluminium structure, 2007

of Peter Eisenman, as well as from tendencies of Spanish architecture that apply and reinterpret folding. From the fine arts, we have gained inspiration from the works of Christian Renonciat, and from a philosophical approach, our inspiration has come first of all from the fold conception of Gilles Deleuze himself. Deleuze devoted an entire book to the exploration of this subject: The Fold, Leibniz and the Baroque (the original French title is Le Pli). As part of the project, György Kunszt the renowned Hungarian architect and philosopher gave a memorable lecture about the philosophical background of architecture, with a focus on folding. His reasoning inspired our students and the author. Next to Tamás Konok, György Kunszt turned out to be another "great master" with a very strong influence on our thinking. He summarised the essence of Deleuze's fold concept in one sentence:

"Folding, for Deleuze, is a magic formula describing the genesis of everything in the universe: the cosmos, the soul, the arts, mathematics, organic and inorganic matter are all the results of the same process, of infinitely differentiated folding" (Kunszt, 1999:p.147).

Deleuze's fold concept is like a new cosmology, able to connect the opposing poles, inside and outside, art and science, nature and culture, material and spiritual.

Folding - problem definition for students of architecture:

"Create forms and spaces in which the ruling creative and

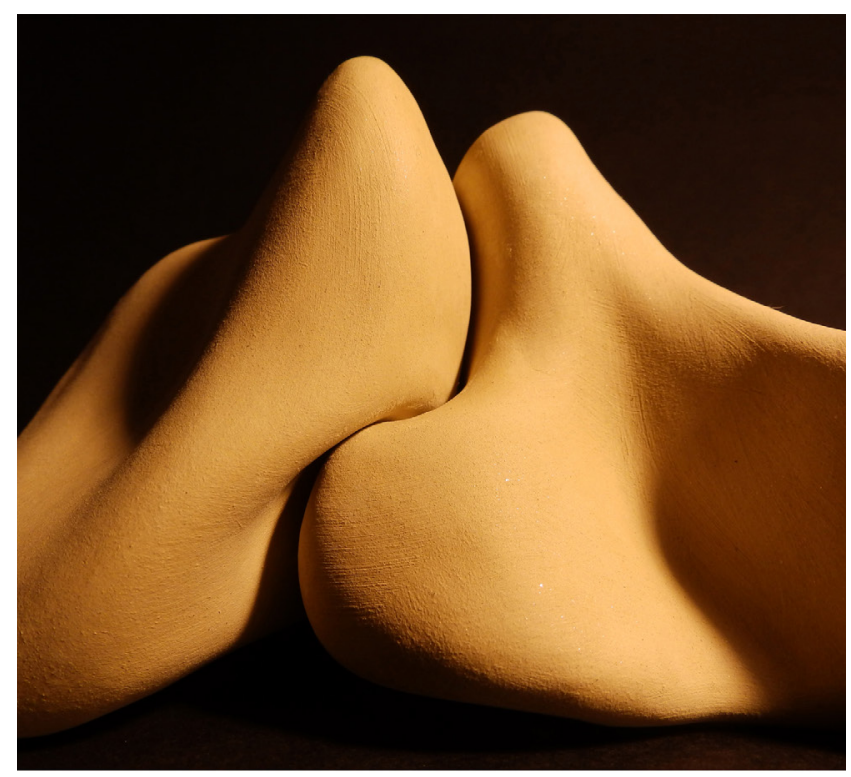

Fig. 8 Vivien Sárkány: Fitamorf, TDK I. prize, 2016.

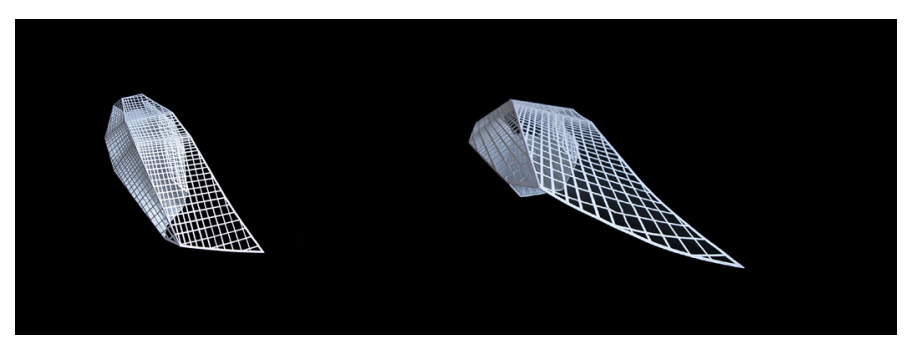

Fig. 7 Zotán Hegedűs: Shell structure, 2012

unifying principle is based on folding. Step outside the orthogonal system and try to create more complex, dynamic structures, which nonetheless do not incline to chaos but toward a perplex harmony."

Students in this project follow the intellectual context of Deleuze's philosophy and experiment with different materials. Aluminium, iron, copper, or plexiglass are all foldable, giving substance and additional meaning to the form. However, the most often used material is paper. Folding at the beginning of the creative process - similarly to origami - is the art of folding paper.

The new geometry of folding - which breaks with the rectangular Cartesian system - and its strong philosophical background, inspires and encourages students to venture into the territory of unique and unexplored forms and spaces.

\section{Ideas and forms}

The third direction of our joint creative and research work is based on the idea of linking conceptual thinking to visual thinking. We start the creative process with one word, a notion or a pair of antonyms. Students first write down their initial personal perceptions and associations to the given notion. They keep reflecting, rethinking these concepts, looking for different ways of interpretation, until they manage to go deep enough to find their individual reading of the concept. This clear idea is what then they try to visualise through a number of different

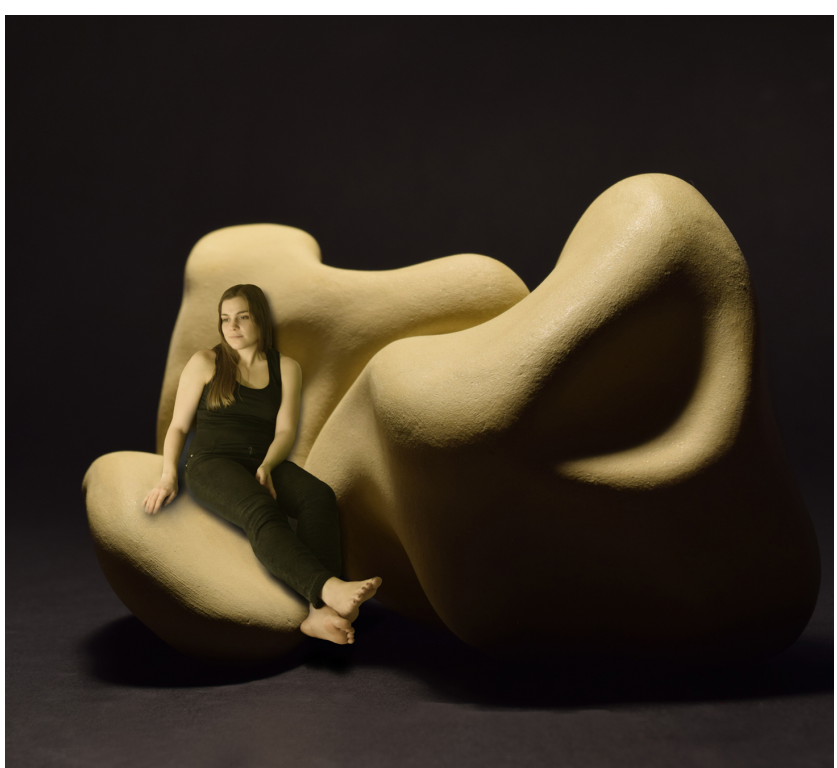

Fig. 9 Vivien Sárkány: Fitamorf Design, 2016. 

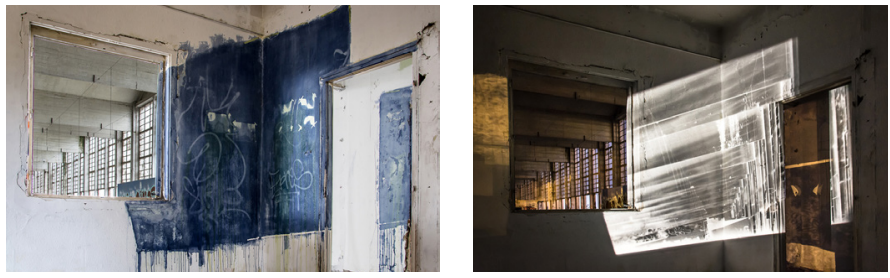

Fig. 10 Zoltán Dévai - Norbert Juhász: Architecture on Photo - Photo on Architecture, OMDK Special prize, 2015.

media: from sculpture or graphics through design or installation to photography or animation.

András Mengyán was the next in the series of great influential masters, an excellent artist and designer with whom we have worked together both in education and in our creative efforts since 2010. From year to year, he has been a great inspiration for how to distil that one clean, artistic idea from an abstract notion, and how to translate it in innovative ways to any given medium.

In 2015, the initial concept for the creative research project was titled: “chaos and order”. Vivien Sárkány’s concept was based on the idea that while the group of the different amorphous bodies could be narrated as chaotic, assembling them would reflect a harmonic order. Working with interlocking amorphous bodies, she has found a beautiful intimacy of forms. She translated these forms into a sculpture and has also applied the concept to a design project. With her sculpture series, named "Fitamorf", as well as her couch design, she won first prize at the 2016 academic edition of the Arts Students' Association annual exhibition.

Hajnalka Kovács, at the end of her thinking process, came to the recognition that chaos and order cannot exist without each other in nature, they always emerge simultaneously. In her 2015 project, she aimed to visualise coexistence, the simultaneous presence of chaos and order. The geometrical form represents order; the doodle imitates chaos. The superposition
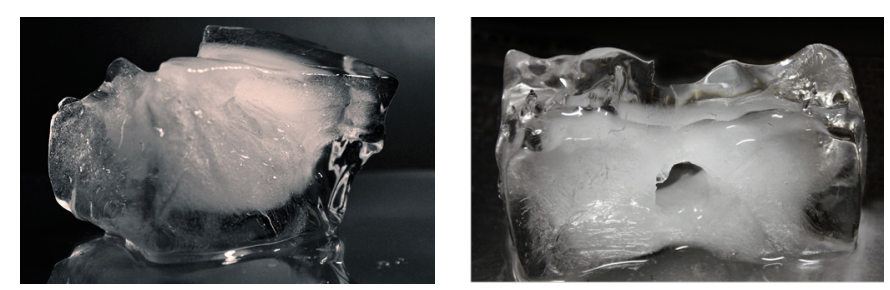

Fig. 11 Gréta Hegyesi: Metamorphosis of Water, TDK II. prize, 2016.

of the two corresponds to the simultaneous presence of chaos and order in two dimensions.

Later she further developed the concept into three dimensions. The surface of the sphere is the order and captured inside the sphere are the chaotic forces. This way, the artwork visualises the delicate balance in which order contains chaos. The artwork reveals a spatial experience very similar to those seen in nature.

In 2013, student Lelle Kovács decided to explore a specific phenomenon: when the perception of reality turns out to be an illusion. Her idea was to visualise this paradox in the form of a concrete pillow; an object that raises epistemological questions of what is reality and how it relates to the pretence? The concrete pillow deceives the onlooker: the sight of the object triggers an illusion of softness, yet, having been made from concrete, it is, in fact, hard and sturdy. The creator compressed her own experiences into the oxymoron of the concrete pillow. With this project, Lelle Kovács won third prize at the 2016 academic edition of the Arts Students' Association annual exhibition.

The following year she lifted the idea from sculpting to the field of product design. Together with fellow student, Adrienn Marxreiter, they created the project called "Soft Concrete". This concrete chair, used as street furniture, gives the impression of being hard and stiff, but once sitting on it, the surface turns out to be soft and pleasant. It provides the surprising experience of sinking into a comfortable chair, due to the concealed springs

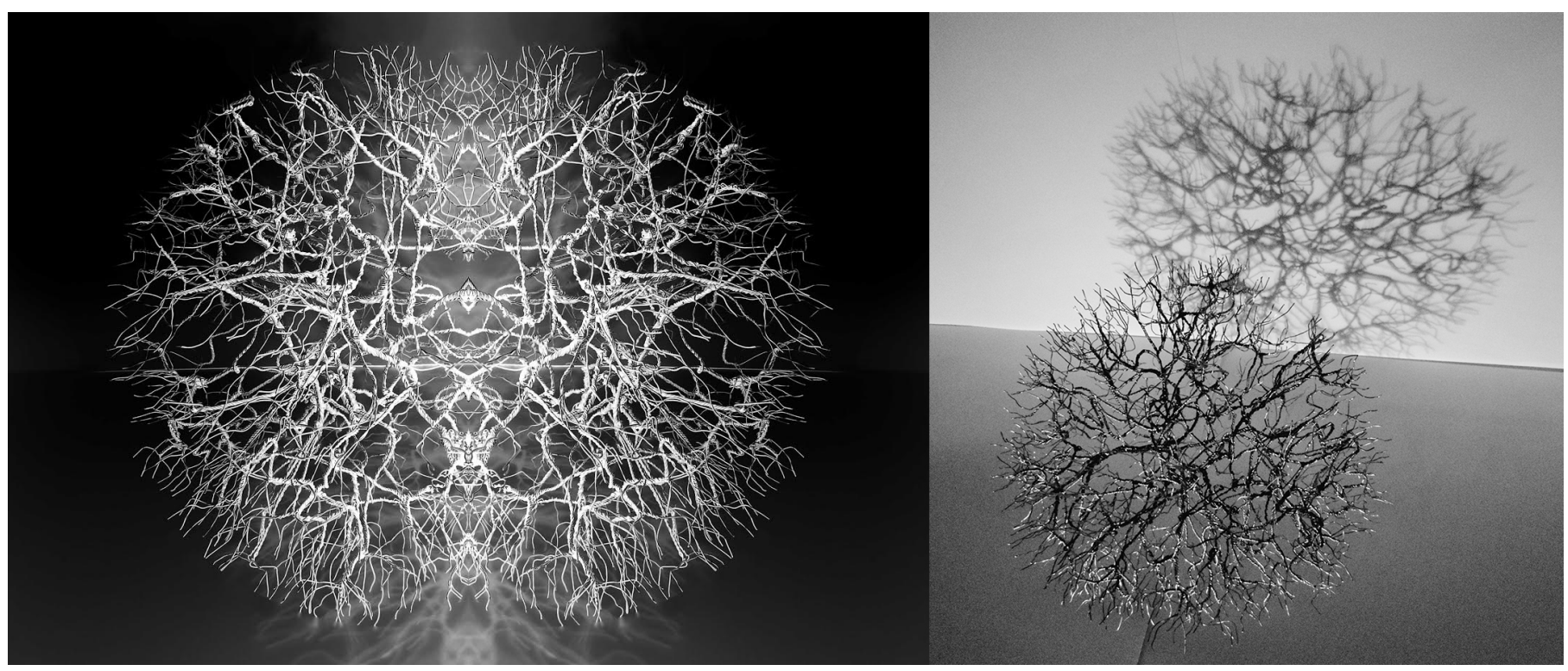

Fig. 12 Hajnalka Kovács: Chaos and Order, 2014. 

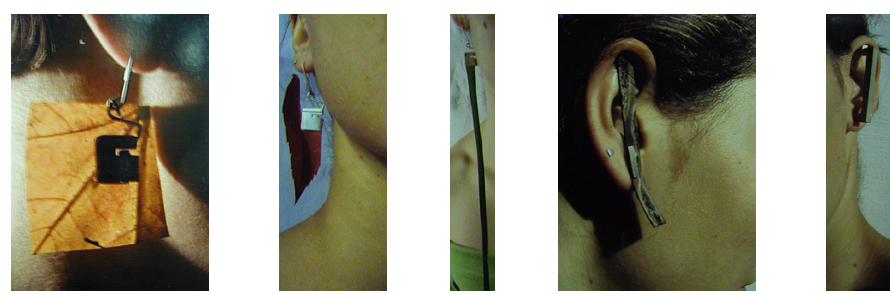

Fig. 13 Lukács Szederkényi: Jewels, OMDK III, prize, 2007.

placed underneath the concrete cubes that cover its surface. The sinking experience makes one wonder and realise how competence and skill can turn hard reality - just as concrete - soft. Their joint project won several prizes, among others second prize in the design category at the exhibition of the National Arts Students' Association and the Hungarian Design Award in 2015.

Lukács Szederkényi's work that won third prize in the applied arts category at the exhibition of the National Arts Students' Association in 2007 also raised exciting ideas. Following a long-term concept, he creates unique jewellery using the crust of cherry tree, grass blades or leaves. His strong connection to nature is revealed in his technique: his creations are made using a single silver clip dressed exclusively with ornaments found in nature; thus, just one blade of grass or a leaf can be turned into jewellery. By replacing the ornaments, his eardrops and pendants can follow the change of seasons. These are transient ornaments: the leaf and the silver would join into a beautiful poetic formation, but that formation is only temporary, the fleeting material withers, fading permanently into nature.

Gréta Hegyesi's concept also gained inspiration from natural phenomena when she invited natural energies in her creative process. The physical event of heat transfer, when hot and cold meet with energy being released and absorbed, is used to create artistic forms in her project. She sculpts her fleeting, unique and unrepeatable forms from ice blocks, using hot water. The

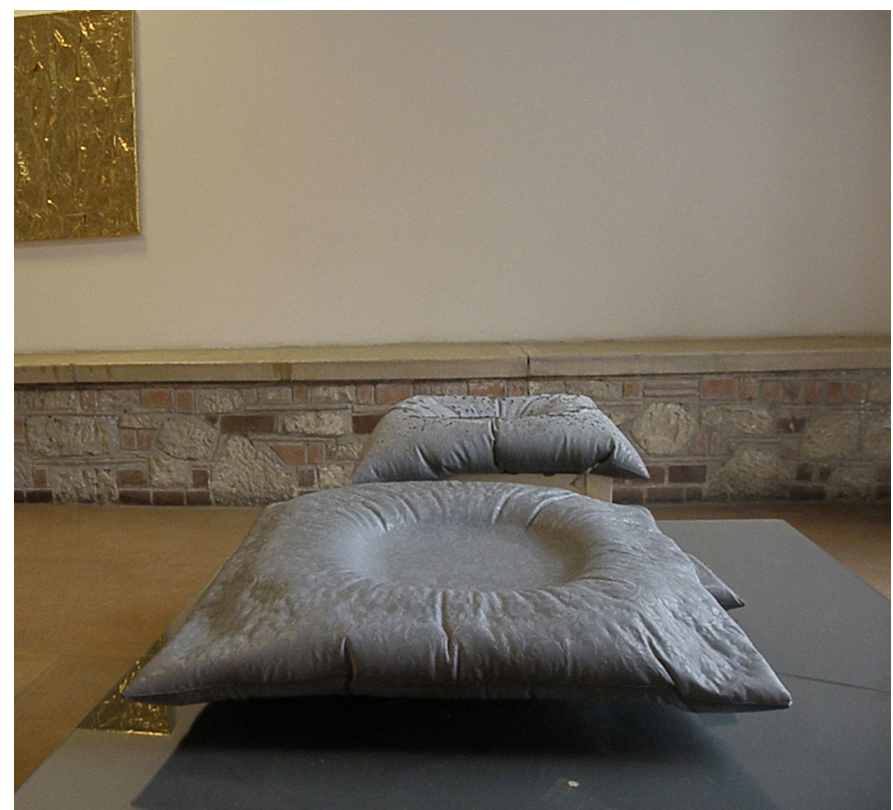

Fig. 15 Lelle Kovács: Concrete Pillow, TDK III. prize, 2013.
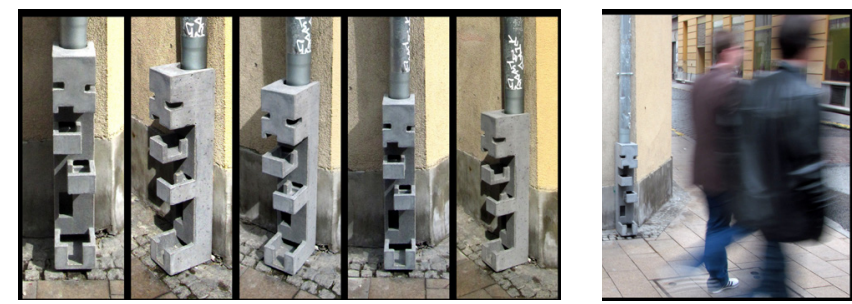

Fig. 14 Zoltán Harmat Szabó: Playful Forms, OMDK III, prize, 2013.

process visualises the metamorphosis of water, as it freezes into solid ice and becomes liquid water again. Due to continuous melting, her sculptures are in a constant transformation until they vanish completely. Her project won second prize at the 2016 academic edition of the Arts Students' Association annual exhibition in the applied arts category.

A distant ironic parallel with the "modern myths of the artistic expansion over the material and social reality" (Hegyi, 1983:p.7) can be observed in Zoltán Harmat Szabó's idea. It corresponds to the heroic efforts of artists of the modern stepping outside of their disciplines to shape society and the social environment - instead of traditional sculptures or drawings. However, contrary to the heroic gestures of modernism, Zoltán Harmat Szabó's post-modern irony only attempts to solve minuscule problems. In his guerrilla art project, he addressed a minor, yet quite common social inconvenience. Gutters on the streets of downtown Budapest often fail to reach the pavement level, thus splashing water all over on passers-by during a heavier downpour. Zoltán replaced such a missing section of a gutter with a playfully shaped concrete sculpture that was designed to relax the water-flow and spare people from the annoyance. An aesthetic solution created with social sensitivity through an anonym intervention, his piece of art blended naturally into its context as if it had been there forever. The project won third prize in the inter-media category at the exhibition of the National Arts Students' Association in 2013.

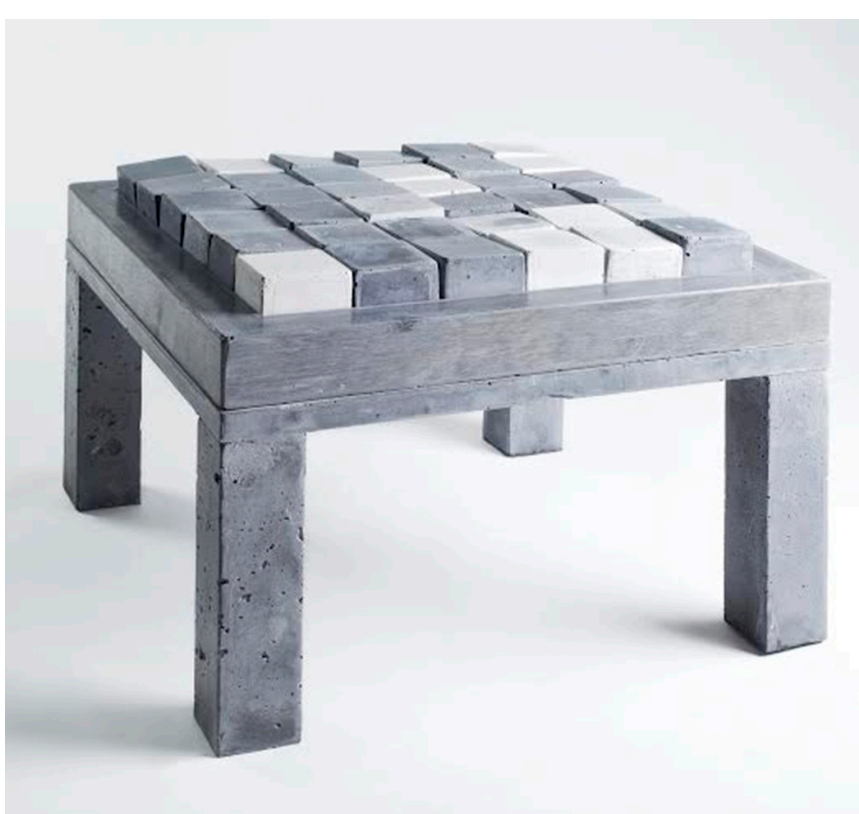

Fig. 16 L. Kovács - A. Marxreiter: Soft Concrete, OMDK II, prize, 2015. 

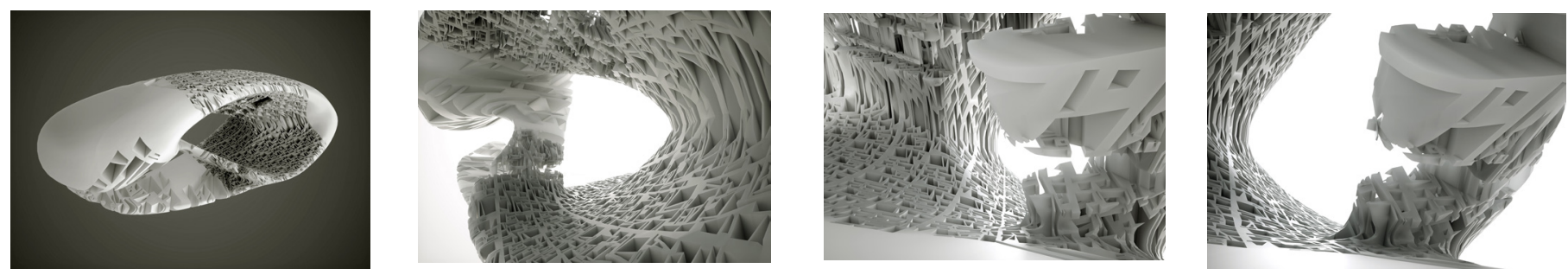

Fig. 17 Üveges -Pálóczi - Czeglédi: Vortex I - II - III - IV, 2017

Zoltán Dévai and Norbert Juhász used photosensitive materials and special photographic technical methods in their experimental installations that aimed to uncover unique connections between architecture and photography. Instead of recording the image of buildings on photos, as done traditionally, they developed photos on the surfaces of buildings. They used special infra cannon to project the negatives of images onto wall surfaces that had previously been treated with a light-sensitive emulsion. These giant photos were developed on different walls or warped around corners in front of the audience as a public spectacle. Their project won the special prize in installation category at the exhibition of the National Arts Students' Association in 2015.

\section{Research Team}

The forth direction of our creative research work began two years ago, when I came to the realization that cooperating with my 3D computer designer colleagues at the department would enable all of us to explore new exciting territories. Working in the virtual space also held great potential for further developing earlier art concepts. For this project, the author teamed up with two excellent colleagues of mine: architect Tibor Pálóczi, who specialised in 3D computer design and architect and 3D artist Péter Czeglédi. Our research group built on interdisciplinary reasoning, the cooperation between different arts and specialities, bringing the accumulated knowledge of the different areas into focus. With this in mind, we concentrated on the experimental thinking and the extending of form creation into the virtual space. Works created in the virtual space were captured and presented on large-scale posters, 3D prints and animations. This research project in part connects to the current teaching programme of the Department of Graphics, Form and Design of the BME Faculty of Architecture, and can be regarded as a logical continuation of previous creative curricular student projects and research programmes. Results of previous experiments have also been incorporated into these artworks.

The philosophy of our work was inspired by the fold concept of Gilles Deleuze, in particular, his interpretation of the different phases of fluidity. In the creation of the spatial structure, we built on the authors previous research on bone structures, and the perception of connections between manual form and form creation and the folding. The computer-aided 3D models are based on the previous research and practical experiments of architect Tibor Pálóczi. Architect and 3D designer Péter Ceglédi was responsible for the computer renderings and animations. Integrating different fields into one research group has resulted in additional benefits. Through a unique synergy of the philosophical inspiration, artistic and architectural approach, manual intelligence and digital technology we managed to create artworks that would have never been born working individually.

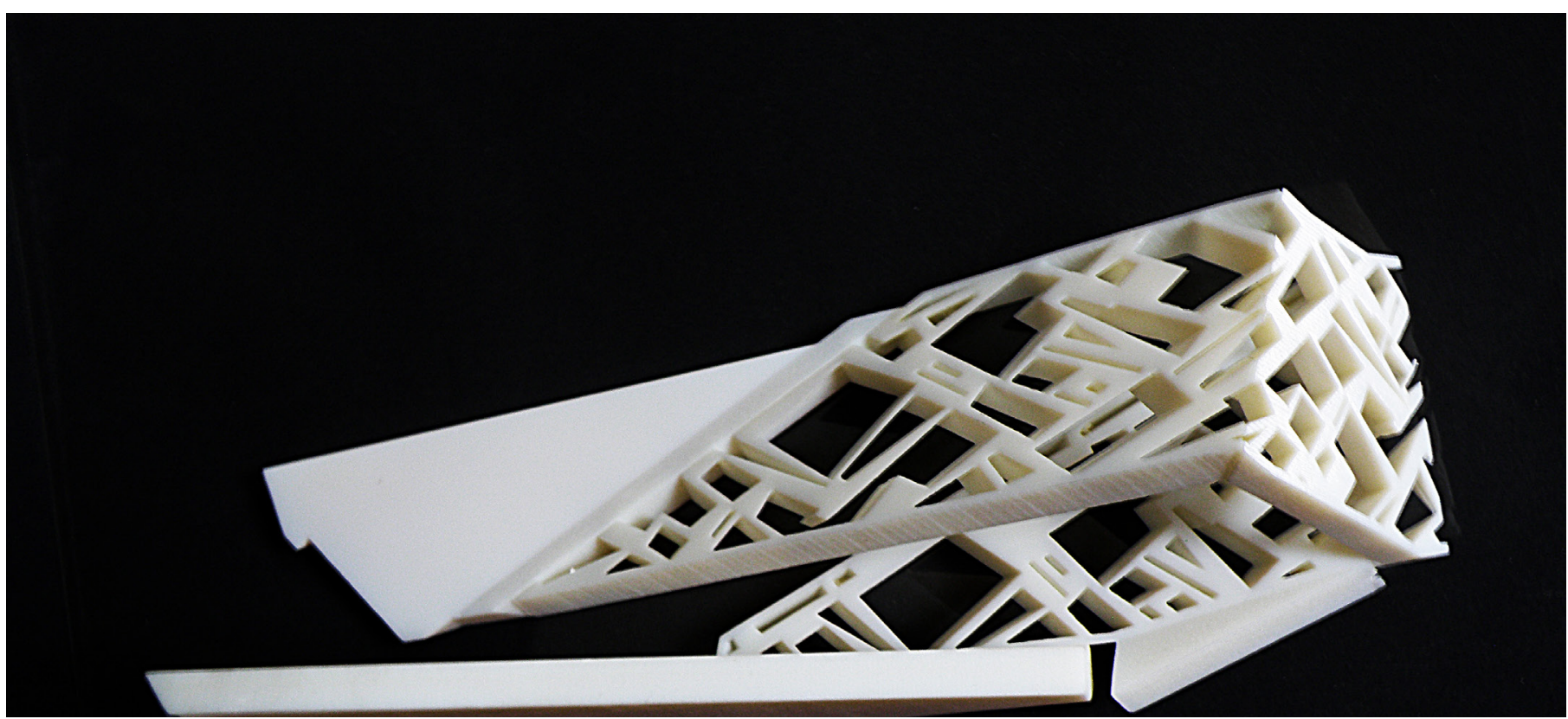

Fig. 18 Üveges - Pálóczi : Interspace, 3D print, 2016 


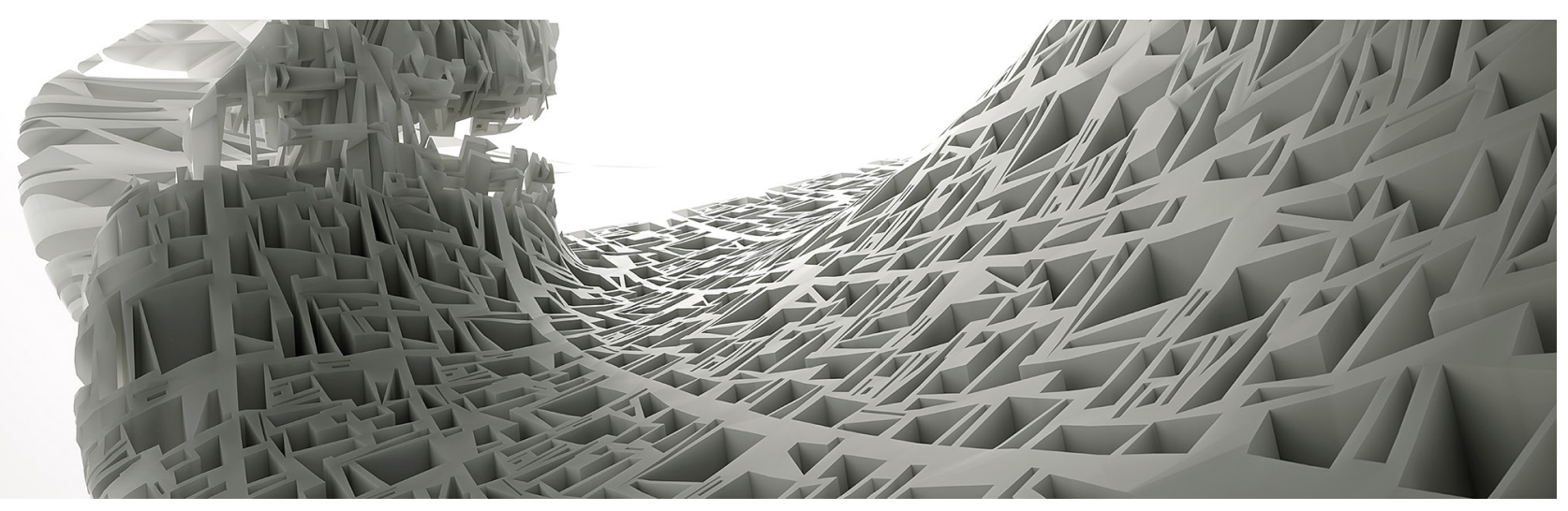

Fig. 19 Üveges - Pálóczi - Czeglédi: Vortex in virtual space, detail, 2017.

On the one hand - still under the influence and inspiration of Deleuze's philosophy - the research group decided to explore the possibilities of the fold concept in the virtual space. On the other hand, the experiments with the multidirectional perforations were attempts to capture a fundamental childhood experience: the problem of existence in the crossfire of contrasting narratives and to remodel the potential intersections of the opposing perspectives in virtual space.

The collision of opposing narratives is translated into space in the form of the destructive encounter and intersection of the different perforation paths, which, thus visualise a consequent thinking model and a spiritual structure. The resulting complex forms, layered structures, have multiple meanings: they are intimate landscapes, thinking models and spiritual structures, whereas the spaces with the elaborate multi-directional perforations represent a unique thinking model that stretches there conciliation of opposing point-of-views to the maximum.

Following these basic concepts and greatly inspired by Gilles Deleuze's “cavern in a cavern" vision (Deleuze, 2006:p,6), our research team started to dive deep into studying porous, spongy textures generated through the perforation of folded forms. In his thesis - often referring back to and citing the baroque philosopher Gottfried Wilhelm Leibniz - Deleuze formulated very inspiring ideas about materials and their spongy structure:

"Matter thus offers an infinitely porous, spongy, or cavernous texture without emptiness, caverns endlessly contained other caverns: no matter how small, each body contains a world pierced with irregular passages, surrounded and penetrated by an increasingly vaporous fluid, the totality of the universe resembling a pond of matter in which there exist different flows and waves" (Deleuze, 2006:p.5).

Our experiments with multi-perforated forms were inspired by this philosophy but mainly governed by our concepts. In the process of the repeated perforation, we reached a point where porosity started to appear inside the previously created porosity, generating a multitude of unpredictable intersecting spaces - in parallel with Deleuze's vision - caverns endlessly contained other caverns. As a result, waving fluidity emerged

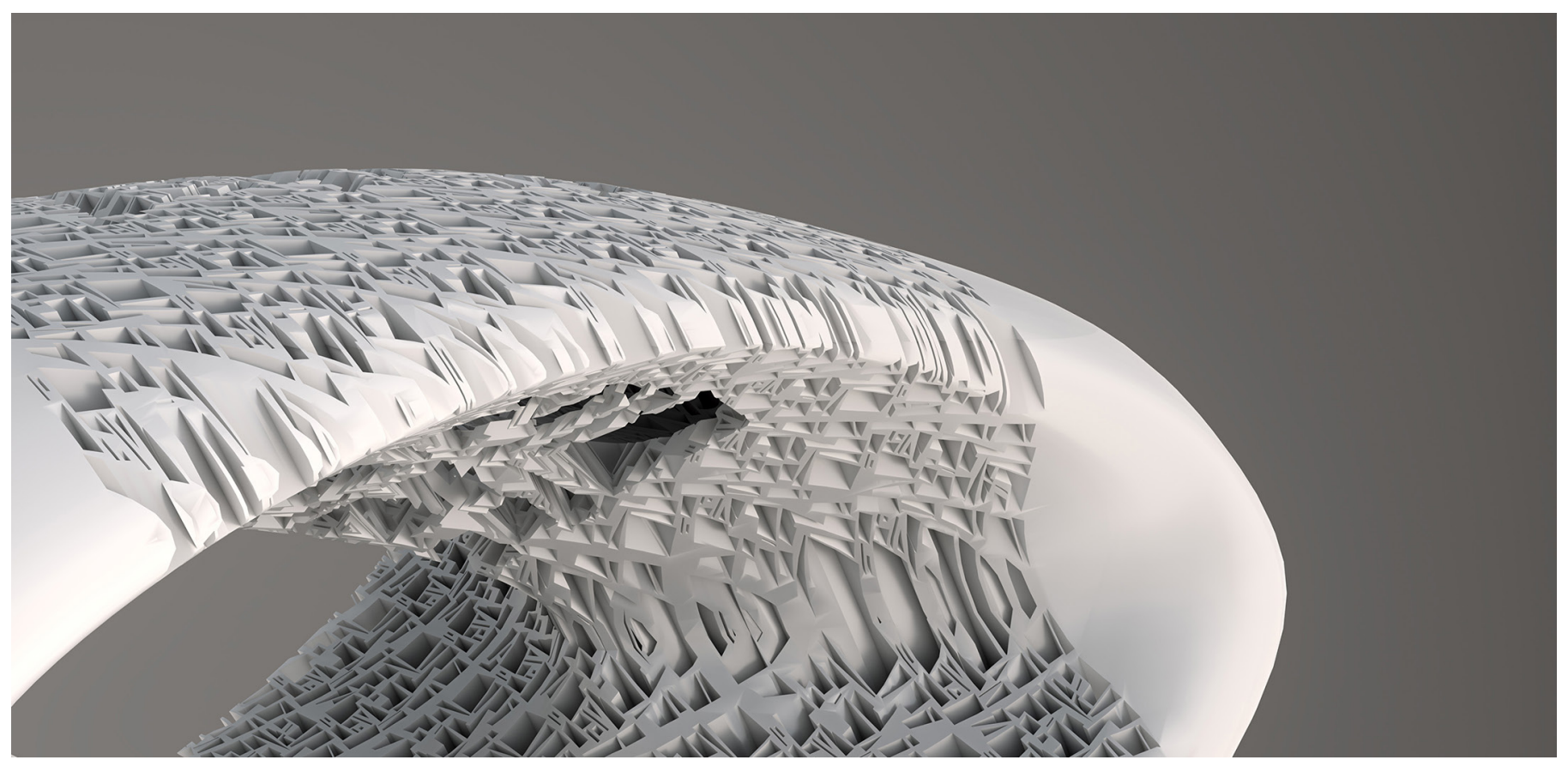

Fig. 20 Üveges - Pálóczi - Czeglédi: Vortex in virtual space, detail, 2017. 


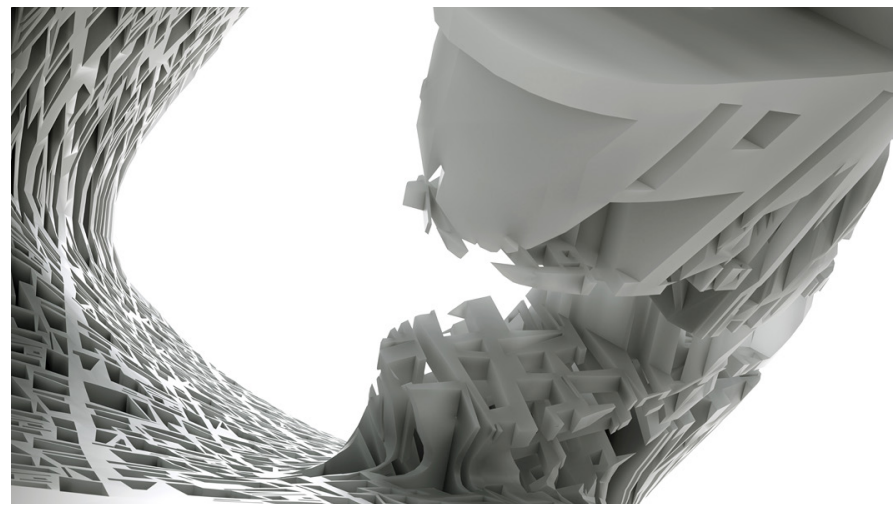

Fig. 21 Üveges -Pálóczi - Czeglédi: Vortex IV, 2017

inside the solid material, and the rigid form seemingly softened. The series of experiments of translating our ideas into space has lead us from the strict geometry of origami and folding to a more elastic spatial and softer formal structure.

Gilles Deleuze emphasised that there is no absolute hardness and there is no absolute fluidity, only a degree of hardness and a degree of fluidity. (Deleuze, 2006:p.6) Sometimes, the folds of the soul are waving; sometimes the waves are going to be a vortex. Sometimes more hardness, sometimes more fluidity. We exist between relative hardness and relative fluidity.

"When a boat reaches certain speed - said Deleuze - the waves becomes as hard as a wall of marble." (Deleuze, 2006:p.6)

\section{Conclusion}

Beyond their individual features, all above mentioned creative and research works of the department conducted on the fields of experimental space and form creation have helped on one hand to introduce architecture students to the various stages of the creative process - from the birth of the idea to the final visualization -, supported individual inventive solutions, and provoked original interpretations and perceptions. On the other hand, in the process of creation, they have familiarized students with the logic of visual thinking and the grammar of visual language. Moreover, they have integrated the learning process into the creative - research experience, since, similarly to how logic of a visual language is best learned through its operation, the individual creative - research experience helps learning most from its process. The borderline between fine arts and architecture was at first employed as a practicing ground that would later initiate individual creative performance, in some cases at a very high artistic level, and students and teachers can join in a mutual thinking process as equal partners. At the same time, the effort in unfolding the

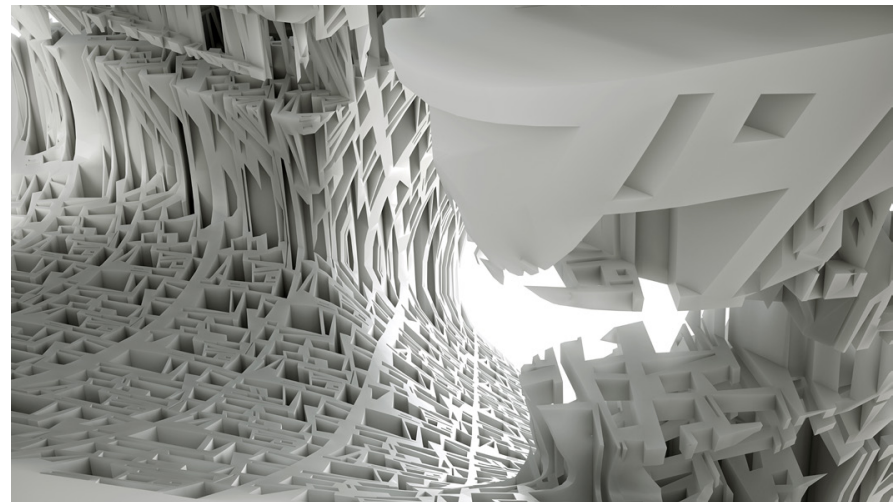

Fig. 22 Üveges -Pálóczi - Czeglédi: Vortex III, 2017

unknown and creating something new and valuable has been shared from the beginning. The more than a decade-long work with students and the joint departmental research group work have verified the hypothesis that an inspiration drawn from the constellation of architecture and fine arts leads to new exciting fields, and the interdisciplinary thinking can bring authentic results. The birth of distinct and successful artworks have proved the presupposition that creative and research work on the borderline of fine arts and architecture is a great practicing field for architecture students in the development of both their visual thinking and their spatial and form creation skills, and the same area has been a fertile ground the department's research group in their experimental thinking and the extension of the spatial and form creation into the virtual space.

\section{References}

Balogh, I. (1983). Az Épitészeti Forma. (The Architectural Form.) Tankönyvkiadó, Budapest. (in Hungarian)

Beke, L. (2002). Megjegyzések egy interjúhoz. (Remarks for an Interview.) In: Konok, T., Baum, P., Beke, L., Mansbach, S. A. (eds.) Konok. (pp. 6-65). Balassi, Budapest. (in Hungarian)

Deleuze, G. (2006). The Fold, Leibniz and the Baroque. Continuum, New York. Dobó, M., Molnár, Cs., Peity, A., Répás, F. (2004). Reality - Concept - Drawing. Müszaki Könyvkiadó, Budapest.

Frampton, K. (2002). A modern épitészet kritikai története. (Modern Architecture: A Critical History.) Terc, Budapest. (in Hungarian)

Heidegger, M. (1995). Bevezetés a metafizikába. (Introduction to Metaphysics.) Ikon, Budapest. (in Hungarian)

Kunszt, G. (1999). Folding and the Max Reinhardt House. In: Kunszt, G., Klein, R., (eds.) Peter Eisenman. (pp. 143-170). Akadémiai Kiadó, Budapest.

Hegyi, L. (1983). Új szenzibilitás. (New Sensibility.) Magvető, Budapest (in Hungarian)

Üveges, G. (2007). Új párhuzamok az építészeti és képzőmüvészeti formaalkotásban. (New Analogies in the Form Creation of Architecture and Fine Art.) PhD Thesis, Budapest University of Technology and Economics. URL: http://hdl.handle.net/10890/1426 (in Hungarian) 